two days, watching carefully her pulse and general condition, until, on October 13 th, she was taking four tabloids daily.

The effect of this treatment was remarkable. On October 17 th (that is, twelve days after commencing the thyroid treatment) she began to show decided signs of improvement, which improvement continued without a break until, on December 24th, 1894, the skin presented its normal appearance, with the exception of a slight tendency to a fine branny desquamation in some parts. On January 8th, 1895, even this had quite disappeared, leaving the skin quite normal in appearance. She ceased to take the tabloids on November 12th, 1894, but as there were slight signs of the pityriasis returning, on December 9th I ordered her to take one tabloid daily. Her skin now (January 12th, 1895) looks quite normal, with the exception of slight patches of eczema on the ankles. whish under local treatment are improving. The thyroid treatment seemed to have no effect on the eczema, and the itching still continues, though $i t$ is much less severe.

Her general health suffered considerably under the thyroid treatment. She became much emaciated, depressed, anæmic, and short of breath (owing to heart failure), but these symptoms soon passed off upon ceasing the tabloids and giving strychnine and wine.

\section{THYROID MEDICATION IN ICHTHYOSIS.}

By ATHELSTANE NOBBS, M.B., Assistant Medical Officer, County Asylum, Morpeth.

THE case which is represented in the accompanying photographs is one of typical ichthyosis in a man who was admitted into the County Asylum, Morpeth, on August 24th, 1891, suffering from general paralysis. The history of the patient, a nomadic lrishman, aged 46, was unfortunately nnobtainable, though he stated that he had suffered from $t$ is skin disease all his life. It is not my present purpose to do more than indicate the lines of treatment adopted for the cure or improvement of the ichthyotic affection, and to a 'rert to certain re ults obtaine $d$ from its use.

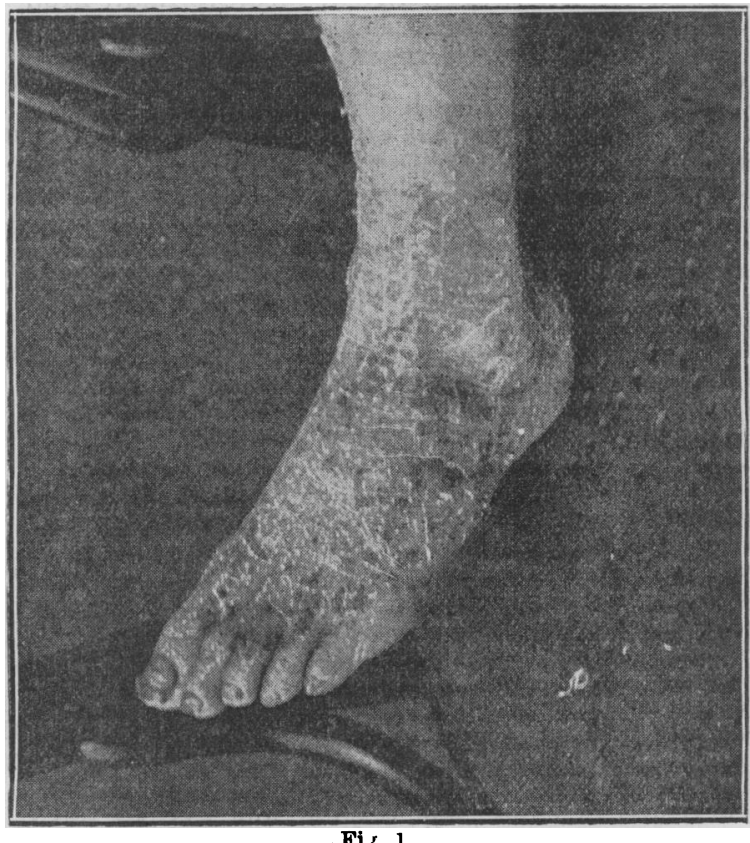

Fis. 1

Towards the end of October, 1893. I commenced by giving the patient 10 minims. thrice daily, of extract of thyroid gland, the preparation of a local firm of manufacturing chemists. It was at this time that photngraph $\mathrm{N}_{0} 1$ was taken, and it represents with great faithfulness the then appearance of the man's left foot.

The following brief notes, taken at the same time will serve as a general description of his condition: "Hair on scalp is iron grey, wiry, sparse, and dry, the skin showing through it. Scurf is readily shed. Face is pitted with old small-pox. The skin is universally very dry, even in the perineum and axillæ. Over the trunk it is desquamating in large flakes. On the elbows. wrists, knees, ankles, and on the dorsum of the metatarsal and metacarpal regions are numerous dingy, greenish squames, varying from the size of a lentil to almost that of a threepenny-piece. These are firmly adherent, and when forcibly detached leave a dry, white scaly base."

The patient being very ataxic and much palsied, he was treated in bed. The extract was administered for about seven weeks, but unfortunately through some misunderstanding was discontinued. Three weeks later it was resumed. and improvement, which at first had been barely appreciable, became marked. The strength of the extract used was 1 in 3 , so that the patient was only receiving the equivalent of 10 grains of thyroid gland. This line of treatment was continued until the middle of March, 1894, when as an experiment tabloids of the gland in a dried state were substituted. The dose was likewise increased to the equivalent of 10 grains of the gland thrice daily, and was broken up among food. Exactly a month later a note was made to the effect that-improvement was marked. Shortly thereafter Photograph No. 2 was taken, and the change for the better is evident.

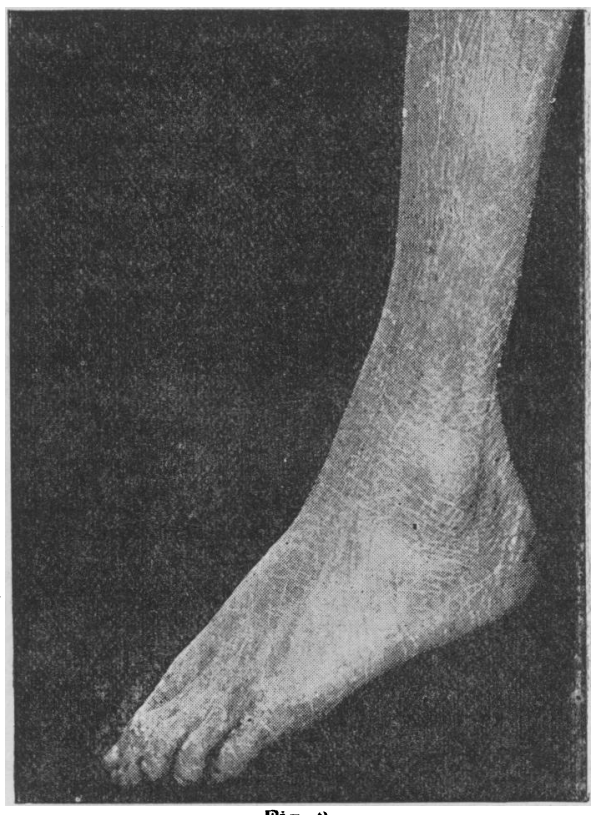

Fig. 2.

On September 1st 1894, treatment was suspended. Except for a somewhat dry condition of the cuticle and a faint scaliness on the exposed surfaces of his joints cure might almost be said to have been effected. The skin of the hands notably, was as soft as that of a child. The patient was now allowed up for increasing periods daily, but whether because of the cessation of the stimulating thyroid treatment or because the effort of being up after so long a rest in bed was too much for him he showed signals of distress, and ten days later went back to bed, the tabloids being resumed.

Apart from the marked benefit to the ichthyosis there can be no doubt that his general health while under this special treatment improved. His appetite became better, his facial expression brighter, and for a time at least his personal habits altered in the right direction, but his graver malady, the general paralysis, pursued its usual progressive course, though the deterioration was decidedly slow. Although the latter remarks may be very wide of the subject of a skin affection the facts to which I have alluded may possibly be not altogether devoid of interest.

At present the dosage is being gradually diminished as the possibility of impairment of the cardiac function consequent 
on a too abrupt suspension of the treatment must not be overlooked. More heroic measures might have been adopted, but the feeble state of the patient had to be borne in mind and the quantities administered considered accordingly.

\section{A CASE OF PSORIASIS OF MANY YEARS STANDING TREATED WITH THYROID EXTRACT. \\ BY HARRY R. PREECE, L.R.C.P.EDIN., I.R.C.S.EDIN., ETC., Birkenhead.}

Miss $P$., aged about 26 , first consulted me about the beginning of March, 1894, complaining of a rash on the face and body, which was accompanied by intense itching. The eruption was of red erythematous character on the face, whilst at the junction of the forehead with the hair there were numbers of yellowish dry scales. On separating the hair the scalp was seen to be pretty well covered with them. On the back the eruption was scaly, the scales being more silvery and the eruption so thick that one could hardly see any natural skin over the whole surface. On the elbows and knees was the true scaly eruption of psoriasis.

The patient's family history is rather interesting, as bearing upon the disease. Her mother was troubled for a very long time with the same affection, whilst her sister has very intractable eczema of the face, for which she has been under my care for some time. She herself tells me that the eruption has been on her body ever since she can remember, but has never appeared on her face before. She has been under treatment, but has never experienced anything but the most temporary relief.

I placed her on iron and arsenic three times a day, with an ointment of boracic acid and vaseline to relieve the irritation. and prohibited meat diet. The face got much better, but the rash remained distinctly visible, the scales still being persistent at the root of the hair and on the body and legs. I then tried unguentum sulphuris co. (B.P.), but still the eruption remained, though not so bad as before.

On April 1st I ordered her to take thyroid extract tabloids (B., W., and (o.), four in the day. I saw her a week later, when there was a marked improvement. The scales were becoming detached from the body, the face was perfectly clear with the exception of a few scales at the root of the hair.

On April 14th I saw her again, and was much struck by the most wonderful improvement in her condition. There were hardly any scales in the hair, and the face was quite well. On examining the body the scales were falling off, leaving a reddish eruption underneath. The irritation was much less. I should remark that at this time I used in conjunction with the tabloids (of which she was now taking six in the day) an ointment of oxide of zinc, boracic acid, and oil of tar. The same evening I was called in to see her, and found her suffering from a severe headache with slight pyrexia, the temperature being $99^{\circ} \mathrm{F}$. I stopped the tabloids for the time being, and ordered antipyrin grs. 10. The next day the headachewas better and temperature normal, but she was giddy when rising. I did not recommence the tabloids until the next day, and then only ordered one a day. In a few days the number was increased to four, and I found that the patient in a short time in her enthusiasm increased the number of her own accord to six. Her condition continued to improve, the only unpleasant symptom being occasional attacks of intense headache. When these came on I invariably stopped the tabloids, much against the patient's wish, as she would rather put up with the headache than stand the risk of her affection gaining ground. In June I examined her body again and found it quite free from scales; the only place where these were present was behind each ear. I now sent her away for change of air, and she went to Leamington, taking her iabloids with her. On her return, in about a month, much to my dismay. I found her much worse. The eruption had returned on the face and head, whilst the irritation was unhearable. However. I determined to stick to the thrroid extract for a little longer before discarding it, but there did not stem to be much progress. I then began to suspect that there must be something wrong with the tabloids, so I wrote to Messrs. Burroughs, Wellcome, and Co., and they kindly sent me a supply. I used these, and was delighted to fird that great improvement took place, the eruption disappeared, also the irritation, and from that time until now she has never gone back, and at the present moment she has not a trace of the disease upon her. I may mention that I received great help from the patient herself, as she faithfully carried out all my directions. I kept her entirely on a light diet, prohibiting butcher's meat, also ordering her to use Wright's liquor carbonis detergens in the washing water. I am hopeful that she is now cured and that the disease will not return.

\section{MEM ORANDA: \\ MEDICAL, SURGICAL, OBSTETRICAL; THERA- PEUTICAL, PATHOLOGICAL, ETc.}

\section{A CASE OF MYXEDEMA TREATED WITH THYROID EXTRACT.}

M. A. single, aged 45, first consulted me in August, 1894. She complained of swelling of the whole body, breathlessness on exertion, etc. She attributed her illness to exposure to cold and wet during menstruation about eleven years ago. Her condition had gradually become worse until the time of coming under my notice.

She presented a general œdematous appearance, especially well marked in the connective tissue around the eyes, also in the lips and hands. The face was pale and waxy, with a circumscribed malar blush. The lips were swollen and translucent. Her tongue was also swollen and appeared too large for her mouth, otherwise the alimentary system was normal. No trace of thyroid gland was to be felt. 'The first sound of the heart was faint but there was no murmur. The respiratory and urinary systems were normal. The skin was dry and harsh, the hair was very scanty. She had had complete amenorrhœa for about eleven years, while during the year previous to its entire cessation menstruation had been very irregular. Her speech was slow and thick and her memory was almost completely gone. Her movements were very slow and her gait uncertain and tottering. The diagnosis was myxœdema.

She was put on thyroid extract tabloids (B., W., and Co.) commencing with one half daily and gradually increasing to three a day.

From the firat I noticed an improvement which has gradually increased until now the odema has entirely disappeared. Her speech has lost its thickness, her memory has returned, and menstruation is now quite regular; in fact my patient says that "she feels as well to-day as ever she did in her life."

I consider this case worthy of publication owing to the prolonged amenorrhoea and the return of menstruation under treatment at so late a period in life.

Walls, Shetland.

MAtTHew Elder, M.B., C.M.Edin.

\section{CINNAMON IN INFLUENZA.}

In the British Medical Jodrnal of March 16th you publish a letter from my friend Mr. C. G. Grant, on cinnamon in influenza. Acting on his theory I have tried the drug in some fifty cases of the disease, and have certainly found it far more useful than the ammoniated tincture of quinine. I give simply $3 \mathrm{j}$ doses of the tincture three times a day. At least thirty of the above cases were benefited, and I generally found from the patients' statements that the pains in the head and back were relieved after three or four doses.

H. A. Stoniam, M.R.C.S., D.P.H. Medical Officer Stepney Union, etc.

THROAT AFFECTIONS IN INFLUENZA.

Is this neighbourhood we are in the middle of a rather severe epidemic of influenza. The symptoms have been aching of limbs with generally rather severe headache, mostly frontal, and this headache has, contrary to my experience in other epidemics, lasted some days after the fever 